\title{
IDEAIS SALAZARISTAS NO BRASIL: IMIGRANTES PORTUGUESES EM FLORIANÓPOLIS E AS REDES DE SOCIABILIDADES EM TORNO DA REVISTA LUSO- BRASILEIRA NA DÉCADA DE 1960
}

\author{
SALAZAR'S IDEALS IN BRAZIL: \\ PORTUGUESE IMMIGRANTS IN FLORIANÓPOLIS AND \\ THE SOCIABILITY NETWORKS AROUND THE LUSO-BRAZILIAN \\ MAGAZINE IN THE 1960S
}

Cristina Iuskow ${ }^{1}$

\begin{abstract}
RESUMO: Este artigo tem como objetivo tratar dos migrantes portugueses em Florianópolis na década de 1960, provindos de Portugal que vivia a época sob o regime do Estado Novo de Antonio Salazar. Nesse contexto surgiu em Florianópolis a Revista Luso-Brasileira, fundada pelo português migrante Mario Fernandes Dias, a qual circulou entre 1961 e 1979. Periódico de variedades com 20 páginas e uma tiragem de 1000 exemplares por edição, mensal e bimestral. Seus mil exemplares eram expedidos para Portugal, Angola, Cabo Verde e outras cidades do Brasil. Nesse artigo tratarei de compreender de que forma a revista se relacionava com portugueses emigrados, quais matérias eram direcionadas a eles e qual teor político ligado ao salazarismo era veiculado pelo periódico. Ainda busco contemplar neste trabalho as maneiras pelas quais portugueses migrantes criavam redes de sociabilidades em torno da revista e do seu próprio grupo.
\end{abstract}

PALAVRAS-CHAVE: Relações luso-brasileiras, Migração, Impressos, Salazarismo.

ABSTRACT: This article aims to deal with Portuguese migrants in Florianópolis in the 1960s, coming from Portugal that lived under the regime of the Estado Novo of Antonio Salazar. In this context, in Florianópolis the Revista Luso-Brasileira appeared, founded by the Portuguese migrant Mario Fernandes Dias, which circulated between 1961 and 1979. Variety journal with 20 pages and a circulation of 1000 copies per edition, monthly and bimonthly. Its thousand copies were sent to Portugal, Angola, Cape Verde and other cities in Brazil. In this article I will try to understand how the magazine related to

\footnotetext{
* Pesquisa decorrente de tese de doutorado, desenvolvida na Universidade do Estado de Santa Catarina, com financiamento da CAPES.

${ }^{1}$ Doutora em História do Tempo Presente pela Universidade do Estado de Santa Catarina (UDESC); Professora na Faculdade Municipal de Palhoça - SC.
} 
Portuguese emigrants, which articles were directed to them and which political content linked to Salazarism was conveyed by the periodical. I still try to contemplate in this work the ways in which Portuguese migrants created social networks around the magazine and its own group.

KEYWORDS: Portuguese-Brazilian relations, Migration, Printed, Salazarism.

\section{Introdução}

Havia na cidade de Florianópolis na década de 1960 uma comunidade de imigrantes lusos não muito expressiva, mas que se esforçava por manter sua coesão ao conservar uma proximidade física nos bairros da cidade. Por meio de conversas iniciais com casais de portugueses em Florianópolis, residentes desde a década de 1960 na capital, foi possível perceber que havia na cidade um grupo que mantinha contatos e procurava comprar ou alugar casas próximas umas das outras. Na trajetória desta pesquisa, resultado da tese de doutorado, conversei ainda por e-mail com alguns portugueses e pessoalmente com um senhor luso-angolano, por meio dos quais obtive alguns esclarecimentos sobre a comunidade lusa em Florianópolis.

Em meio a essa comunidade, um de seus membros, Mario Fernandes Dias, fundou em Florianópolis a Revista Luso-Brasileira publicação que circulou entre 1961 e 1979, a qual era editada em Florianópolis, mas distribuída entre cidades no Brasil, Portugal e cidades africanas nas chamadas Províncias Ultramarinas ${ }^{2}$. Havia correspondentes da revista espalhados em Angola, Cabo Verde, Portugal, Ilha da Madeira e no Paraná. Por seu formato, capa e conteúdo, o periódico apresentava-se como de entretenimento, mas também como informativo e noticioso, com 20 páginas impressas, contendo ilustrações, notícias e imagens variadas que ilustravam muitos de seus espaços.

Mario Fernandes Dias deu entrada no Brasil em janeiro de 1959. Era nascido em Lisboa e residente nesta cidade no momento de sua partida para o

\footnotetext{
2 "O Ato colonial de 1930, [...], é reformulado na revisão constitucional de 1951. No novo texto os termos "colónias" e "império colonial" foram substituídos por "províncias ultramarinas" e "ultramar". Pretendia-se transmitir a ideia de que, em conjunto com a metrópole, formavam uma unidade política, a "nação pluricontinental e multirracial portuguesa" (CASTELO, 2015:514).
} 
Brasil. Foi "admitido em território nacional em caráter permanente", conforme consta de sua "Ficha Consular de Qualificação" (Figura 1), ou seja, veio com as condições necessárias para permanecer no país. Nesse documento consta ainda que em Portugal exercia a função de "encadernador". Pelo que se sabe, por meio de entrevistas suas para a própria Revista Luso-Brasileira, em Portugal trabalhava para a revista $O$ Século Ilustrado. Ao chegar a Florianópolis, após a união com Terezinha Cascaes, nascida em Florianópolis, logo veio o surgimento da revista e juntamente com ela a criação de uma rede de colaboradores da publicação.

Em Lisboa, de acordo com uma pequena nota em Luso-Brasileira em agosto de 1961, já trabalhava como contista e crítico de cinema havia 15 anos. $\mathrm{Na}$ ficha consular consta a profissão de encadernador, possivelmente ele já realizava as duas funções e a de encadernador fosse a principal. Em Portugal seu primeiro trabalho como escritor, na revista $O$ Século Ilustrado ${ }^{3}$, no ano de 1950, foi a publicação do conto Minha vida e meus pecados, para o qual se assina como Mario Dias Sanches que era o sobrenome do avô, conta. Em uma entrevista para a Luso-Brasileira na seção Falam os escritores, diante da pergunta Como nasceu a ideia de publicar a Revista Luso-Brasileira? Mario Dias relata que após chegar a Florianópolis conversou com o proprietário de um jornal com a proposta de fazer aos domingos um suplemento feito por ele e seria anexado ao jornal, mas "o citado diretor do jornal, embora achasse boa a ideia não pôde me atender. Resolvi, então, fazer uma revista. Falei com minha esposa, que é brasileira, então sendo eu português, formou-se um laço e veio a Luso-Brasileira" (LUSO-BRASILEIRA, 1963: 7).

\footnotetext{
3 “A revista $O$ Século Ilustrado, surgiu como um complemento semanal do jornal $O$ Século. Este jornal lisboeta foi publicado todas as manhãs durante 97 anos (1880-1977). [...] Criada em 1933, e extinta em 1989, O Século Ilustrado captava o interesse maioritariamente do sector feminino, dado o teor social que nela se inseria: notícias da actualidade, estórias das celebridades, anúncios publicitários, grandes reportagens, sector humorístico e espaço didático. A primeira publicação data de 7 de novembro de 1933, ao passo que a última é semanal, 21 a 27 de julho de 1989." (Flama e O Século Ilustrado, análise de Outubro 1968 - História do Jornalismo, Faculdade de Letras da Universidade do Porto, p.21) Disponível em:<http://portfoliodigitalinesguedespiment.weebly.com/uploads/1/2/4/7/12475277/histriajorna lismo_trabalhofinal.pdf> Acesso em 20 de fevereiro de 2018.
} 
Figura 1 - Entrevista de Mário Fernandes Dias à Luso-Brasileira

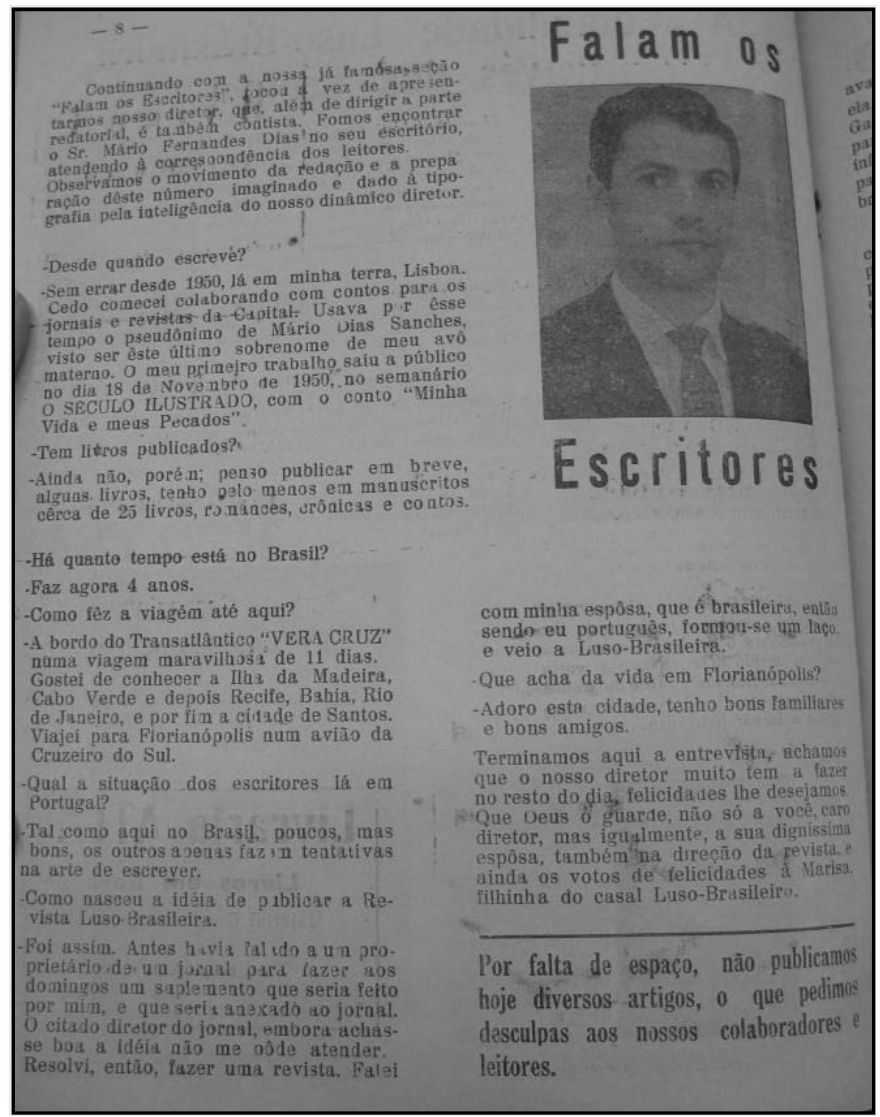

Fonte: Luso-Brasileira, n.3, agosto, 1961, p.1.

Mário Fernandes Dias nunca mais retornou a Portugal. Quando chegou a Florianópolis, também por esta época, fundou uma associação para portugueses e brasileiros denominada Associação Luso-Brasileira, com o intuito de reunir os portugueses e brasileiros interessados em encontrar-se. De acordo com um de seus conterrâneos que vivia na cidade, chamado António Galego, ${ }^{4}$ natural de Miranda do Douro, a convivência com ele na associação nem sempre foi fácil, pois não havia uma discussão das atividades que gostariam de realizar e em geral eram organizados apenas jantares, o que não agradava a todos. Pagavam uma mensalidade que deveria ser utilizada para a revista e para os custos das atividades da Associação, mas alguns dos membros não concordavam com os rumos que tomava a associação e julgavam não haver nela um objetivo

\footnotetext{
${ }^{4}$ Conversa realizada na casa do sr. Antonio Galego no dia 30 de março de 2017.
} 
definido, o que fez com que muitos deixassem de participar. Após alguns anos decidiram fazer nova votação e escolher outra direção para a associação, o que fez com que Mario Dias se afastasse. Após a escolha da nova diretoria, que ficou a cargo de João Lupi com a ajuda de Manoel Gomes, ambos portugueses, a associação passou a ter mais membros, chegando a haver necessidade de utilizarem uma sala com mais capacidade, por volta de 80 pessoas.

Tal associativismo estava presente entre a comunidade lusa em Florianópolis ainda de várias formas, uma delas era o costume de habitarem perto uns dos outros em alguns bairros da cidade. Afirma Alice Lang sobre a prática da criação de associações (2003: 115-16) que elas "têm o papel de amparar, reunir a comunidade e preservar as tradições" e também são de "grande importância para o governo português em sua proposta de construção de uma nação alargada, porque representam o único meio de comunicação com uma comunidade marcada pela dispersão". Ou seja, eram meios pelos quais o regime localizaria e estabeleceria comunicação com os emigrados.

Não obstante os desencontros e desentendimentos com a comunidade portuguesa em Florianópolis, Mário Dias mantinha a publicação da Revista Luso-Brasileira, a qual segundo suas palavras em editorial para a revista: “[...] a realização deste empreendimento foi o resultado de um sonho, e valeu a pena ter sonhado, em que era diretor de uma revista que fosse um laço de amizade entre Brasil e Portugal” (LUSO-BRASILEIRA, 1961: 1).

A sua trajetória na cidade de Florianópolis pode ser gradualmente compreendida por meio de informações colhidas na própria revista e por meio da fala de colaboradores da publicação contatados, integrantes da comunidade luso-brasileira em Florianópolis. Essa rede de contatos na cidade era formada por pessoas com vínculos com Portugal, moradoras de Florianópolis, em geral proprietárias de estabelecimentos comerciais no centro da cidade. Parte-se do conceito de redes elaborado por John A. Barnes o qual afirma que seriam estas "um conjunto de relações interpessoais concretas que vinculam indivíduos a outros indivíduos" (1987: 167), conceito este que elucida a formação das redes sociais entre migrantes portugueses em Florianópolis, a qual os vinculava por 
meio da formação de relações interpessoais variadas. O grupo de migrantes lusos na cidade era razoavelmente estável e homogêneo. A inserção de Mário Dias na cidade se fez a partir dessas redes e também de familiares da esposa, Terezinha Cascaes. Pouco a pouco essa rede de relacionamentos alargou-se e ele foi se tornando relativamente conhecido, bem como a revista, e por meio dessa visibilidade cada vez mais comerciantes da cidade passaram a anunciar no periódico.

Os textos publicados na revista versavam sobre temas variados, dentre os quais, moda feminina, lidas domésticas, conteúdo sobre pais e filhos, contos, poesias, piadas, receitas culinárias, eventos sociais e colunas sociais. Mas, havia também notícias densas sobre a política portuguesa e brasileira. Portanto, para isso, os editores através dos correspondentes traziam notícias sempre atualizadas de Portugal, fossem estas econômicas, políticas ou artísticoculturais. Por meio dessas notícias, informações e crônicas que permeavam o periódico, difundiu-se ao longo dos dezoito anos da publicação a "cultura portuguesa”, ou uma cultura política de Portugal que chegava aos emigrados portugueses em Florianópolis e nas cidades em que houvesse portugueses emigrados alcançados pela revista. Além desses era importante também que brasileiros se identificassem com as histórias de Portugal e com as notícias que chegavam de lá, que pudessem se familiarizar com elas a ponto de querer apoiar seus propósitos no contexto da manutenção do império ultramarino salazarista. O sentimento de "cidadania" do seu fundador, no sentido de manter viva a ligação e a rede de apoio ao regime do Estado Novo de Portugal, sobretudo entre os portugueses, mas também entre brasileiros, foram fatores que possibilitaram a criação e manutenção do periódico que surgia.

Concomitantemente à reunião da comunidade portuguesa na cidade, os editores da revista formaram uma rede de sociabilidades que associou grupos variados de pessoas para escreverem na publicação sobre temas diversos. No decorrer da pesquisa conversei com alguns portugueses que vivem em Florianópolis, e que também conheceram Mário Dias e a Luso-Brasileira. Embora a utilização da história oral não tenha se realizado como metodologia 
nesta pesquisa, alguns contatos por e-mail e conversas pessoais foram efetuadas. Recorrer à fala dos imigrantes para realizar parte da pesquisa a imbuiu de vivências reais expressas pelo testemunho ocular, narrativas que não se obtém nas páginas dos "testemunhos dos documentos escritos" (LE GOFF, 1990: 5). É significativo o que afirma Fernando Kolleritz sobre o peso da testemunha a qual "carrega o passado para o presente, o que aconteceu num lugar geográfico para outro; sustenta assim o real, suporta-o e o garante [...]" (2004: 75). É o passado que se apresenta pela voz de quem viu os acontecimentos. Koselleck nos lembra que "todos os que ainda vivem ou sobreviveram servem então como testemunhas oculares ou de ouvir dizer; podem ser interrogados, e seus relatos podem ser avaliados criticamente" (2014: 268). Tais relatos são, no entanto, apenas uma parte daquilo que se quer conhecer, serão mesclados, ponderados, justapostos quando da análise do conjunto das fontes.

Não foi possível quantificar o número de portugueses em Florianópolis a época, mas nesses contatos foram citados alguns nomes de lusitanos que aqui viviam e que já faleceram. Da comunidade que havia na cidade no início da década de 1960, a maioria havia chegado a Florianópolis entre 1955 e 1960. Dos nomes que foram citados nas conversas, é possível contar ao menos 15 portugueses, muitos provindos de Miranda do Douro, região de Trás-osMontes, ao Norte de Portugal. Alguns deles já se conheciam naquela região, portanto, ao chegar tinham um pequeno grupo de conterrâneos conhecidos. Havia certo conflito com portugueses da região de Lisboa, pois afirmavam os mirandeses que os lisboetas os consideravam "gente do interior". Até hoje a aproximação maior entre os portugueses que vivem na cidade é feita por conta da sua origem regional e de classe, mais do que pelo fato de serem oriundos de Portugal. Grande parte dos emigrantes de Miranda do Douro vinha de um mundo rural. Lá trabalhavam a terra, e diziam muitos deles que "só não passavam fome", mas não tinham perspectiva de mudar de vida. Sobre as roupas que usavam, "não se sabia mais o que era calça e o que era camisa" de tantos remendos. Não tinham possibilidade de continuar a estudar além dos 
estudos primários, pois precisavam ajudar os pais na lavoura. A perspectiva de vir para o Brasil se mostrava como uma possibilidade de mudarem de vida. Para isso, no entanto, havia alguns trâmites burocráticos em Portugal antes da viagem, sendo necessária uma carta de chamada, uma idade mínima, não ser analfabeto e, afirma Antonio Salgado, um dos depoentes, "não podia ter um dente podre na boca". No entanto, ao perguntar sobre qual imagem tinham de Salazar afirmavam que ele havia tirado o país da miséria, colocado "as coisas" no rumo certo. A relação com a vida que levavam, de poucas perspectivas não entrava nessa avaliação, portanto.

Algumas das pessoas com as quais entrei em contato chegaram a Florianópolis na década de 1970. Vieram já em outro contexto da vida política de Portugal, após a Revolução dos Cravos, em 1974, a qual pôs fim ao Estado Novo. Muitos deles eram luso-angolanos que vieram para o Brasil e em seguida para a cidade de Florianópolis para afastar-se das guerras de independência em Angola, devido à difícil situação que se apresentou aos portugueses no país africano. Aqui chegando, a interação com os portugueses já instalados na cidade era facilitada pela rede de sociabilidades que havia se construído, no entanto se desvendou uma distinção entre os portugueses recém-chegados que possuíam formação acadêmica e eram de regiões mais centrais de Portugal e os portugueses que haviam chegado à década de 1950, vindos do Norte de Portugal, da zona rural. Os nomes mencionados por uns e outros fazem parte do grupo de conterrâneos com profissões e níveis de vida semelhantes, portanto não era o fato de serem portugueses que os unia, mas muito mais o fato de serem da mesma região e de mesma classe social. Antonio Galego, já mencionado, expôs o fato de que os portugueses da região de Lisboa que viviam em Florianópolis demonstravam uma certa "superioridade" em relação aos que vinham do Norte de Portugal. Em Florianópolis esses dois grupos se distinguiram nas atividades em que se empenharam, sendo que o primeiro grupo exerceu atividades ligadas ao comércio no centro da capital, muitos dos quais ainda subsistem, enquanto o segundo exerceu atividades ligadas ao ensino, advocacia e construção civil. 


\section{A escrita como missão}

A missão proposta no primeiro editorial da Luso-Brasileira nos faz compreender o quão representativo para o projeto de emigração do Estado Novo este evento poderia ser. Essa percepção se dá ao fazermos uma incursão mais profunda sobre o papel do emigrante português, mais particularmente pelo português Mario Fernandes Dias. Sobre a missão pode-se afirmar que tinha início quando o emigrante deixava Portugal, pois ao fazê-lo não se desligava de seu país, levava-o consigo, dava seu apoio ao regime onde quer que estivesse. Dava provas da sua cidadania mesmo distante do seu país, a 'cidadania' tal como era pensada pelo Estado Novo, na qual o "português como cidadão tem a única função de referendar o poder constituído [...] parte integrante de um recorte nacional, no qual ele não possui, contudo, nenhum poder decisório" (PAULO, 2000: 44). Ser cidadão nesse contexto era estar ao lado do regime, corroborando suas ações sem críticas, sem reivindicar participação.

O Brasil era visto como "país irmão", expressão evocada para acentuar uma determinada relação que se buscava construir entre os dois países e sua condição de dividirem grande parte de suas histórias e de seu idioma. Para Portugal, sobretudo no contexto político da década de 1960, afirmar ter o Brasil como país irmão era uma forma de apresentar essa relação permeada de raízes, boas relações e familiaridade. Eduardo Lourenço, sobre esta relação, que não considera próxima, lembra as diferenças entre o discurso português sobre o Brasil e a forma como o Brasil vê Portugal: "o discurso português sobre o Brasil [...] é uma pura alucinação nossa, que o Brasil — pelo menos desde há um século - nem ouve nem entende" (LOURENÇO, 2001: 136-137). Para o autor a distância que se colocou entre o Brasil e Portugal não é percebida da mesma maneira pelos dois países, pois o Brasil se encontra bem mais distante de Portugal. A isto refere que "[...] o Brasil parece [...] cometer um parricídio, mesmo inconsciente, vivendo-se, como realmente se vive, nos seus textos, nos seus sonhos, nas suas ambições planetárias, como uma nação sem pai" (LOURENÇO, 2001: 136-137). Para o autor há motivos para os brasileiros 
comportarem-se como se fossem filhos de si mesmos. Não seriam os brasileiros os responsáveis por colocar 'entre parênteses' as suas raízes portuguesas

como recusa da relação obcecante de uma origem vinda de outro lugar. São os próprios portugueses a fonte da diluição dos laços com Portugal. Tudo se passa como se tivessem ido para o continente brasileiro para por lá se perderem. Por lá se perderam. No Brasil, Portugal está em todo lado e em lado nenhum (LOURENÇO, 2001: 158).

Os portugueses que chegaram ao Brasil se transformaram logo em brasileiros, não se constituíram num pai de um novo povo, mas eram eles os pais de si mesmos. Essa reflexão de Lourenço o leva a concluir que a comunidade luso-brasileira é um mito inventado unicamente pelos portugueses, e que não é minimamente vivida pelo lado de cá do Atlântico. Diante desse contexto é possível compreender que a luta pelo fortalecimento de laços entre brasileiros e portugueses é uma tarefa que vai na contramão dos eventos históricos passados entre os dois países.

Neste sentido, no cenário de migração de portugueses para o Brasil, há um constante interesse em imprimir no português que emigra uma marca possível de ser transportada para qualquer local e que o lembrará de seu papel no interior do corpo da nação Portugal. Para Heloísa Paulo, é como se o cidadão português aparecesse como uma representação 'metafórica' da 'Nação'. Portanto, a função do português é uma só, vivendo em Portugal ou como emigrante. E continua a autora:

\footnotetext{
os emigrantes, assim como os seus filhos, são, em princípio, considerados portugueses e sujeitos [...] à autoridade do regime. [...] o Estado Novo vai recorrer a [...] meios para que a sua mensagem seja incorporada pelos portugueses emigrados (PAULO, 2000: 53).
}

Esta não era uma tarefa simples, pois para manter a influência e garantir a propaganda do regime em um país distante como o Brasil havia a necessidade de um engenhoso aparato institucional. Esse aparato entrava em funcionamento já no país de origem, pois havia todo um conjunto de fiscalização do regime por meio de entrevistas a quem desejava emigrar, que impedia, por exemplo, a vinda de famílias inteiras para o Brasil, evitando assim que os laços com 
Portugal fossem cortados; também o estado de saúde era averiguado, mas mais importante ainda era a certificação de que os emigrantes fossem alfabetizados, sendo que em 1955 é criada a "exigência formal do exame da $3^{\text {a }}$ classe do então ensino primário elementar" (PAULO, 2000: 72). Havia a preocupação de que os emigrados não "desprestigiassem a Nação", e não prejudicassem o "bom nome do país”. É importante destacar que os custos da viagem ao Brasil não eram baixos e o processo não era simples. Uma viagem para o Brasil na década de 1950 era o equivalente a seis vezes o salário de um trabalhador de baixa renda em Portugal, além de outras taxas obrigatórias. Isto para dizer que "quem emigra está longe de ser o proletariado rural” (PAULO, 2000: 79).

Além das exigências e controles feitos ao emigrante ainda em Portugal, era preciso, portanto, que as ligações continuassem na terra de destino. Para este fim, direcionados aos portugueses no exterior foram utilizados panfletos de propaganda, boletins, folhetos informativos e também os discursos de propaganda. ${ }^{6}$ Tipos variados de mensagens para alertá-lo sobre a nova terra, consolá-lo por deixar Portugal e lembrar ao emigrante das suas obrigações.

Em 1947, por meio do Decreto-Lei n. 36.558, em 28 de Outubro foi criada pelo Governo português a Junta de Emigração, ligada ao Ministério do Interior, com o objetivo de regular os fluxos emigratórios em consonância com os superiores interesses nacionais (GALVANESE, 2013: 52). Um vasto material será produzido por esse órgão no que se refere à emigração e aos emigrantes. O caderno Nós, os Emigrantes..., produzido pela Junta de Emigração em 1954, tinha distribuição gratuita e constituía-se em uma espécie

\footnotetext{
${ }^{5}$ (Preâmbulo do Decreto ${ }^{\circ} 16.782$, de 27 de Abril de 1929, in: Diário de Governo, $\mathrm{I}^{\mathrm{a}}$ série, $\mathrm{n}^{\circ}$ 95, p.1047. apud, PAULO, 2000:71) Desde 1929 os decretos que estabelecem as exigências para os emigrantes vão sendo alterados, pois na prática essas exigências não são atendidas. Em 1941 o Anuário estatístico mostra que naquele ano 607 emigrantes que entraram no Brasil eram analfabetos, cerca de $1 / 4$ do total, apesar das disposições legais contrárias em ambos os países (PAULO, 2000). No entanto a preocupação com a qualidade do emigrante permanece pelo tempo em que a emigração ocorre.

${ }^{6}$ O Boletim de Emigração, publicado pelo Comissariado Geral dos Serviços de Emigração, é destinado a fornecer informações gerais para quem emigra, como descrição dos contratos de patronatos de emigrantes, índice de preços das passagens, listagem dos agentes autorizados, possibilidade de colocação para os emigrantes e decretos relacionados com a emigração [...]. Os panfletos de propaganda da Junta de Emigração, destinados a elucidar o emigrante a respeito do processo emigratório (PAULO, 2000: 86).
} 
de manual para quem emigrava. Escrito na primeira pessoa do plural, seus textos parecem mais um relato dos emigrantes num pronunciamento coletivo. "Nós, os EMIGRANTES, aspirávamos de há muito, a possuir um LIVRO que nos fizesse sentir a PÁTRIA junto de nós [...]" (JUNTA DE EMIGRAÇÃO, 1954: 5). E continua empregando termos referentes ao português que emigrava com forte apelo nacionalista e de comprometimento com Portugal: irradiação de lusitanismo, trabalho persistente, alma soberana. Finaliza o prólogo com o trecho: "são esses portugueses emigrantes que irão tornar-se Cidadãos do Mundo, sem deixarem de ser, nobremente, Cidadãos de Portugal!" (JUNTA DE EMIGRAÇÃO, 1954: 9). A emigração foi assumida pelo Estado como sendo de alguma forma vantajosa para o regime, vista como um mal necessário, mas também como última solução para diminuir o excesso populacional e aumentar o rendimento da população (SANTOS, 2014: 178). Quem emigrava não poderia ser "perdido de vista" pelo regime. E a ele era recordada sua missão de cidadão de Portugal, tal como exorta o manual:

Os verdadeiros Emigrantes, - que não são os agitadores facciosos, - indesejáveis no próprio país, - mas sim os trabalhadores inteligentes e abnegados que, - a custa da separação do seu lar [...] ao verem-se longe de Portugal, congregam-se em prestimosas associações, por eles fundadas, em que expandem o seu patriotismo, mais com obras do que com palavras, no pendor natural $[\ldots]$ de praticarem o bem e serem úteis ao seu próximo (JUNTA DE EMIGRAÇÃO, 1954: 30).

Exorta-se o trabalho, a abnegação, a busca por associação com outros portugueses e a fidelidade ao regime. Associar-se, precisamente, para manter sua portugalidade que remetia ao Portugal de Salazar. E assim os emigrantes eram cercados pelo governo português para impedi-los de se engajarem em ideologias contrárias às ideias propagadas pelo Estado Novo. E são as palavras do próprio Salazar que serão utilizadas para falar das semelhanças entre Brasil e Portugal, o que não ocorre de maneira fortuita.

Acho que o Brasil, do tamanho dum continente, exuberante de riquezas, estuante de atividades, e com a força da sua unidade política e moral, constitui o mais precioso exemplo do êxito dos nossos métodos: Portugal e o Brasil, durante 
séculos, tiveram vida comum (JUNTA DE EMIGRAÇÃO, 1954: 10).

Elogiar o Brasil significava também elevar Portugal e transformar o português emigrante em um protagonista da exuberância que então se tornou o Brasil, nas palavras de Salazar. E Portugal, por meio da comunidade de falantes da língua portuguesa, ligava-se ao Brasil, participava da sua história, pelos laços "inquebrantáveis" com esse país. O emigrante representava o laço que unia os dois países, é quem aproximava a "grandeza" do Brasil a de Portugal.

Ao Brasil - um dos maiores países do mundo - ligam-nos laços espirituais, morais, étnicos e linguísticos inquebrantáveis [...]. Mais de oitenta mil indivíduos falando a língua portuguesa constituem hoje a comunidade lusobrasileira no mundo (JUNTA DE EMIGRAÇÃO apud PAULO, 2000: 89).

Para quem deixou o país, essas eram leituras que possibilitavam uma maior aproximação com o regime português e com a nação. Criava-se por meio desses elementos que apelam às raízes nacionais, ao patriotismo e à tese da "afetividade histórica" - pela qual existiria um laço afetivo natural de irmãos entre os dois países - um laço com o emigrado que ao mesmo tempo e discretamente o inseria, ou melhor, não o deixava de fora das demandas políticas de Portugal com o Brasil. A referência à língua como o liame da comunidade luso-brasileira, o elemento central além de um passado histórico em comum, foi algo com frequência citado em textos e discursos do Estado Novo. As histórias conectadas entre esses dois povos foram possibilitadas e reforçadas porque havia e haveria sempre o inexorável fator linguístico. Utilizálo como elemento formador de "laços" entre brasileiros e portugueses foi crucial para fortalecimento da comunidade luso-brasileira. A importância da língua está no

[...] seu papel na comunicação e na interconectividade, por ser um veículo de transmissão de ideias e de inovações tecnológicas, mas também de dados culturais como a herança e a consanguinidade, os laços de familiaridade e os sistemas de coesão social sedimentados ao longo do passado histórico (FERNANDES, 2008, apud MACIEL, 2010: 30). 
Utilizar esse veículo era uma forma de criar a comunidade lusobrasileira, que não correspondia a uma realidade naturalizada tão somente por haver portugueses e brasileiros que se relacionavam no interior do Brasil ou de Portugal, mas uma realidade que era preciso construir, criar um sentimento de pertença a esta comunidade.

$\mathrm{O}$ intenso fluxo emigratório português nos séculos XIX e XX “[...] levou Portugal à adoção de uma concepção alargada de país, considerando não o território, mas o povo de língua portuguesa. É um conceito de nação dispersa [...], fazendo com que as relações de Portugal com tais comunidades se acentuem" (LANG, 1999, apud OLIVEIRA, 2003: 3). Para além do Tratado de Amizade e Consulta assinado em 1951, firmado no âmbito das relações governamentais, a amizade, elemento fortalecedor da comunidade, deveria ser construída por meios que fossem capazes de produzir um sentimento de ligação a uma comunidade que não fosse somente um ajuntamento dos falantes da língua portuguesa, mas que fossem unidos por interesses nacionais, políticos e ideológicos.

O papel da Revista Luso-brasileira entre os imigrantes portugueses em Florianópolis durante o regime Salazarista

O regime português acentuou suas relações internacionais por diversos meios e as revistas de variedades também foram parte dessas estratégias de inclusão, aproximação e ligação do Estado Novo com o emigrado e também apoiador do regime no Brasil. As revistas poderiam ser um forte elo entre Portugal e o português ausente, pois poderia envolver toda a família nos mesmos temas que vão de culinária até ações do governo de Salazar. Ao mesmo tempo em que atraía a mulher emigrada, com os temas tradicionalmente a ela direcionados, é dada à leitura também dos homens, pressupondo-se que se interessavam por temáticas políticas e econômicas. A Revista Luso-Brasileira pretendia-se direcionada a todos na família, e diante disso é possível caracterizá-la como uma revista de variedades. Ela não se autodenominava de variedades e nem política, e não se apontava como uma revista neutra sem teor 
político. As notícias e informações apareciam conforme os editores acreditavam que fosse necessário tratar determinados temas, políticos ou não.

As ideias políticas, religiosas e morais, entre outros temas, estão dispersas nas páginas das revistas nas variadas notícias e conteúdos e muitas vezes passam sem serem notadas. Afirma Sirinelli que "uma revista é antes de tudo um lugar de fermentação intelectual e de relação afetiva, ao mesmo tempo viveiro e espaço de sociabilidade, e pode ser entre outras abordagens, estudada nesta dupla dimensão" (2011: 249). A reunião de um grupo de intelectuais em torno da Revista Luso-Brasileira criava esses espaços de sociabilidade, formadores e divulgadores de ideias que naquele momento fermentavam no espaço político nacional e internacional, sobretudo no que concerne à relação entre Brasil, Portugal e as colônias africanas.

A textualidade da publicação aqui pesquisada direcionava-se ao público em geral, mas é possível perceber que privilegiava bastante o público português, buscando criar e acentuar laços transatlânticos. Uma boa parte das matérias nos primeiros anos da publicação era voltada ao público português. Ao intitular uma matéria Belezas e costumes de Portugal e junto dela uma foto do rio Tejo, o editor está ao mesmo tempo trazendo uma recordação para o leitor português e o conhecimento das terras portuguesas para o leitor brasileiro. No texto citado o próprio Mario Dias escreve sobre as belezas e encantos de cidades em Portugal, sobre as festas e sobre locais.

A prática de anunciar as peculiaridades das terras de Portugal como atividade propagadora do país para o mundo não se dava por acaso. $\mathrm{O}$ turismo no Estado Novo, sob a tutela de António Ferro (1933-1948), diretor do SNI, ganharia um aspecto de "arma de propaganda político-ideológica do Estado Novo, instrumento privilegiado para o reconhecimento internacional" (RIBEIRO, 2015: 99). Para isso se promoveu a "estetização da cultura portuguesa que investiu na idealização do bucolismo", em que a vida camponesa era "um espaço de excelência para a transformação de uma Nação pretensamente genuína e pitoresca" (CABRITA, 2010: 130). Esse bucolismo e a vida camponesa eram imagens que se buscava transportar para o emigrante 
português e também para quem quisesse conhecer Portugal, associando-o a um país construído sobre a terra, voltado para os ideais do campo, de trabalho, família, o Portugal pitoresco. Ao iniciar a década de 1950 - década em que houve o maior volume de migrações para o Brasil -, já com António Ferro afastado do SNI, a atividade turística terá um papel diferente do que vinha ocupando até então. Passaria a ser considerada uma área de atividade econômica relevante, e não mais encarada como "forma de um constructo ideológico" tal qual havia sido delineado por Ferro (GONÇALVES, 2012: 101).

Os registros das belezas naturais e do folclore de Portugal se apresentavam quase como algo corriqueiro e sem valor, todavia transportavam uma carga emocional e de forte enaltecimento da nacionalidade portuguesa, algo que naquele momento era de vital importância para o Estado Novo, pois significava atrair os olhares de potenciais turistas para Portugal e ainda reunir portugueses em torno do imaginário da portugalidade. Por meio destas narrativas, publicações deste tipo sustentavam a identidade portuguesa, pois traziam à lembrança o passado no além-mar, os locais que vinculavam os leitores a Portugal a sua origem e que compunham o ser português. "Ser português e afirmá-lo é, portanto, para o imigrante, um traço que, para além de definir a sua identidade, o distingue, para o bem ou para o mal, da sociedade envolvente", lembra Paulo (2000: 250). Buscar uma distinção e manter essa distinção, criar um ligame entre os portugueses emigrados e ainda construir uma identidade portuguesa como apoiadores do regime na ex-colônia, era o que desejava o Estado Novo português para seus emigrados no Brasil. Isso ocorria com mais força e nitidez em cidades maiores como o Rio de Janeiro e São Paulo, onde havia um grupo maior e mais homogêneo de portugueses. Já em Florianópolis, o grupo de lusos era disperso e muitas vezes indiferente à agremiação. Contudo, por meio do editor, a publicação procurava constituir uma comunidade com o intuito de trazer Portugal aos seus patrícios.

Os textos da revista vão assim se constituindo. Na seção Curiosidades para você, Portugal está de novo presente no conteúdo e mais explicitamente 
ainda na seção Portugal em Marcha, em que quatro notícias políticas sobre o país se apresentam e numa delas a situação da questão colonial com o título Benção Norte-americana - A penetração do comunismo em Angola. Esse era um tema recorrente em Luso-Brasileira e é possível perceber a posição política colonialista adotada pela revista, num consentimento com o direcionamento do regime português. Para Heloísa Paulo (2000: 160): “[...] a cultura popular, juntamente com o culto da história ou profissões de fé ideológicas, transformase em elemento de agregação e de um sentimento de 'nacionalidade' que se torna mais forte fora de Portugal". A autora se refere amplamente às associações e seus grupos folclóricos, o que certamente não era o caso de Florianópolis. Contudo, as "profissões de fé ideológicas" que menciona apresentam-se repetidamente na publicação quando se posiciona a favor do colonialismo, e a favor do Estado Novo em Portugal, ou na defesa das ações governamentais de Salazar. Não menos importante que as profissões de fé como elemento do "sentimento de nacionalidade", haverá o culto da história, outra temática frequente nas páginas da Luso-Brasileira. Sentimento de nacionalidade que passa pela capacidade de imaginar a nação, de acordo com Benedict Anderson (2008). Imaginar a nação distante, a comunidade portuguesa espalhada pelo "império ultramarino" formador da nação, imagem esta que deveria ser resguardada e estimulada por meio de imagens e lembranças da sua história. Manter o português que emigra próximo ao regime, próximo da sua "pátria", como seu representante e como alguém compromissado com a ideologia do regime era algo necessário para a sua sobrevivência nos anos que se avizinhavam. Diante desta percepção é emblemática a afirmação:

Deixamos Portugal, por amor a Portugal. [...] Levámos connosco o seu glorioso Nome a outras Nações, em que o queremos ilustrar com as nossas vidas consagradas ao Trabalho e com a lealdade e dedicação que nos merecem esses Países que aceitam a colaboração portuguesa para o seu Progresso (JUNTA DE EMIGRAÇÃO, 1954: 5).

Entende-se que o emigrado está comprometido com sua nação através do trabalho e lealdade, por Portugal e pelo Brasil. A Revista Luso-Brasileira ia permeando suas páginas com temas que fizessem essa conexão entre emigrados 
e seu país de origem, entre brasileiros e sua história com Portugal, e entre os dois povos. Estratégias que o Estado Novo português fazia uso para sustentar o regime e todo o seu ideário por meio da tentativa de unir a totalidade dos seus habitantes em torno de um conjunto de ideias que remetia ao sentimento lusitano, as raízes rurais, aos "heróis" do passado, ao líder.

Na matéria intitulada Glórias para o Brasil e Portugal, o texto em questão, escrito por Mário Dias, abordava os "heróis" do ar portugueses Gago Coutinho e Sacadura Cabral, que em 1922 retornavam do Brasil na primeira viagem aérea que atravessou o Atlântico Sul. Narrava-se: “A cidade [Lisboa] despertava para o contentamento, o que vinha provar estar o Brasil mais unido a Portugal, pois de futuro os aviões cruzariam o Atlântico" (LUSOBRASILEIRA, 1961: 7). O texto integral relembra aos portugueses os seus personagens importantes, seus "heróis", uma forma de imaginar a nação e este pequeno trecho em particular evidencia a união almejada entre os dois países. Na mesma página, numa pequena nova seção denominada Caricatura, lembra o "herói" dos ares do Brasil, Santos Dumont. Ao abordar resumidamente sua vida e sua morte afirma que "a sua ideia valeu, o seu invento foi aceito, e finalmente a sua figura pequenina não mais saíra da história dos heróis brasileiros" (LUSO-BRASILEIRA, 1961: 7). Uma página para relembrar aos brasileiros e portugueses seus heróis dos ares, dos personagens que permeiam a história dos "países irmãos".

A imagem do ditador português Antonio Salazar vai aos poucos sendo inserida na publicação, trazendo ao imaginário social de leitores e leitoras de Portugal e do Brasil a presença de um Salazar que fala aos seus cidadãos, em Portugal ou fora dele. Cabe aqui considerar o conceito de imaginário social proposto por Bronislaw Baczko, o qual o entende como

[...] um aspecto da vida social, da atividade global dos agentes sociais, cujas particularidades se manifestam na diversidade dos seus produtos. [...] através dos seus imaginários sociais, uma colectividade designa a sua identidade; elabora uma certa representação de si; estabelece a distribuição dos papéis e das posições sociais; exprime e impõe crenças comuns; constrói uma espécie de código de "bom comportamento", designadamente através da instalação 
de modelos formadores tais como o do "chefe", o "bom súbdito", o "guerreiro corajoso", etc. (BACZKO, 1985: 309)

A partir de Baczko é possível compreender como o imaginário social do emigrante português reproduz e reforça seus gostos e sentimentos, mesmo num país distante, mesmo inserido numa cultura diferente da sua. A publicação, ao remeter imagens e aos contextos históricos e políticos da nação portuguesa nas matérias, realiza um trabalho de fortalecer a identidade nacional lusa. E assim, já no seu primeiro número, abaixo de uma visível foto de Salazar, inicia-se o texto Salazar falando à Nação.

Falando para todos portugueses, o Sr. Prof. Oliveira Salazar se dirigiu à nação, com um notável discurso que foi um exemplo de patriotismo, de inteligência e de dignidade. Esclareceu a nação quanto ao presente e ao futuro, contou serenamente o panorama atual do mundo, as críticas e ofensas ao Ultramar Português, a sua voz foi a voz da Pátria, avisando os atrevidos que Portugal não dorme, o alerta e a nossa força, será o suficiente para dar ao mundo uma lição de que somos vigilantes e unidos aos povos que nos admiram e respeitam. (LUSO-BRASILEIRA, 1961: 10)

O texto não tem data nem local, seu discurso atravessa o tempo e as fronteiras. O importante aqui é que sua mensagem chegava aos portugueses emigrados, apresentando os problemas que Portugal ainda sofria no cenário internacional por conta de sua política nas colônias do Ultramar, lembrando dos países que hostilizavam esta política. E adverte que a ligação com os povos que o "admiram e respeitam” é a sua força. O Brasil é um desses países, sua histórica amizade com Portugal deveria ser reforçada para que conseguisse perseverar a política africana. As relações com o Brasil começavam a sofrer as consequências da Política Externa Independente (PEI) ${ }^{7}$ e, portanto, as relações com a comunidade portuguesa no Brasil se tornavam estratégicas para que a sua influência política não esmorecesse. E conclui o texto da Luso-Brasileira: "Salazar mais uma vez acordou os debates na ONU (Organização das Nações Unidas). Daqui desta terra brasileira, portugueses e brasileiros nos unimos para

\footnotetext{
7 Política externa que buscava se distanciar de parâmetros ideológicos nas negociações políticas e econômicas com países do mundo. Por esses parâmetros o Brasil negociará com países do bloco capitalista, mas também do bloco socialista, numa proposta pragmática da política externa; tal proposta vigorou entre 1961 e 1964.
} 
fortalecer mais e mais os laços de amizade..." (LUSO-BRASILEIRA, 1961: 10). Havia uma preocupação grande do regime do Estado Novo com relação às guerras de independência iniciadas em Angola, portanto, mais ainda os laços de amizade com o Brasil necessitavam ser fortalecidos, sobretudo no que diz respeito à atuação conjunta na ONU. A revista se colocava como intermediária da voz de Salazar entre os portugueses no Brasil. Ao mesmo tempo em que atingia os brasileiros sensibilizando-os para os propósitos do salazarismo, para os quais a revista se colocava como defensora.

$\mathrm{Na}$ continuação, Luso-Brasileira, em texto escrito por Mario Dias, apresenta um conjunto de temas bastante emblemáticos e de maneira simbólica neste primeiro número. $\mathrm{O}$ extenso texto foi intitulado Relembrando o Infante Santo quando Portugal e Brasil deram as mãos, e nele Dias relembra Juscelino Kubitschek, Infante Dom Henrique e da saudade da terra. A matéria começa recordando a visita de Juscelino a Portugal, que se realizou em agosto de 1960 nas comemorações do V Centenário do Infante Dom Henrique. Mario Dias relembrava um episódio ocorrido havia oito meses, mas não informava a data na matéria:

Vai longe aquele dia em que o povo luso, recebia a ilustre visita do Dr. Juscelino de Oliveira. Tendo em vista que a nossa revista é um laço de união que une os dois povos irmãos, eu pretendo gravar esse acontecimento na lembrança de milhares de portugueses (LUSO-BRASILEIRA, 1961: $15)$.

A função da revista era a de manter viva na lembrança dos portugueses a ligação fraternal entre portugueses e brasileiros, a qual havia sido uma marca de governos passados, e que deveria continuar sendo a marca entre os dois povos. Prosseguia: "o Brasil visitava a terra mãe, ia levar-lhe um abraço de saudades de outros tantos portugueses, espalhados por este torrão brasileiro, por esta terra que Cabral descobriu" (LUSO-BRASILEIRA, 1961: 15). A saudade da terra é um tema recorrente na narrativa da revista e, como português emigrado, o editor acabava por colocar-se na condição de cidadão português saudoso da sua terra, mas que, no entanto, atuava como um representante do governo na ex-colônia, trabalhando para fortalecer o enlace entre os dois países. 
E continuava:

Lisboa viveu uma festa digna, o Tejo com as suas barquinhas, ao longe o monumento a Cristo-Rei, desta forma meu coração parece estar batendo fora do normal, talvez porque estou recordando a minha terra natal, a minha querida e sempre bonita Lisbôa, as ruas limpas, o palácio de S. Bento onde mora o Sr. Presidente do Consêlho Dr. Oliveira Salazar, o professor que com a sua inteligência tem levado Portugal a destacar-se no mundo inteiro (LUSO-BRASILEIRA, 1961: $15)$.

Ao mesmo tempo em que expressava sua saudade da terra natal, o autor se colocava como voz que representava a de outros portugueses e portuguesas que estão longe de Portugal. Junto com a saudade e das belezas das ruas de Lisboa, revelava sua impressão positiva do ditador Salazar que nestas linhas são bastante evidentes. E ainda neste tom elogioso: "Pela mão de tão brilhante alma o meu Portugal distante continuará em paz e em prosperidades. Além de tudo a minha missão é unir mais os dois povos irmãos" (LUSO-BRASILEIRA, 1961: 15). E mais uma vez salientava a sua missão, em primeira pessoa, que era também a da publicação. É um texto repleto de significados, de um emigrado assumindo a condição de 'cidadão', dentro dos moldes impostos pelo Estado Novo e, portanto, de alguém que se coloca como peça nessa engrenagem do regime, de propaganda, apoio e da rede de cidadãos portugueses.

A referência aos heróis portugueses se apresentava neste número de forma incisiva e, ao abordar o Infante Dom Henrique, toma-o como mais um herói que unia brasileiros e portugueses. Salienta:

Ele marcou com a sua inteligência o rumo do mundo nos 500 anos seguintes ao do seu nascimento. Com a sua idéia, os missionários foram para a África, ali espalharam a semente das Sagradas Escrituras. Deus se serviu do Infante para evangelizar outras gentes e desbravar outras terras.

A história de Portugal está repleta de heróis, as suas páginas nos contam as dinastias, os reis e suas gerações, e depois o descobrimento do Brasil, este mundo novo na sua marcha de progresso e paz (LUSO-BRASILEIRA, 1961: 16).

O descobrimento do Brasil estaria ligado a este evento que inaugurava um tempo de "progresso" para esta terra. A revista, como uma publicação que era distribuída também em colônias portuguesas na África, agia como defensora 
da atividade colonizadora, contrária aos movimentos de independência que começavam a se estabelecer e mobilizar em Angola. Elogiar o empreendimento da Escola de Sagres e toda a atividade colonizadora portuguesa, bem como o "progresso" daí advindo para a ex-colônia Brasil era uma forma de corroborar com o regime salazarista. Ao mesmo tempo em que elogiava a aproximação do ex-presidente JK a Portugal e toda a amizade construída entre eles, mostrava aos leitores brasileiros o quanto é justificável essa união, pois o Brasil teria muito a reconhecer pelo trabalho dos "heróis" portugueses.

Os heróis e personagens portugueses serão temas recorrentes na Revista Luso-Brasileira. Retratá-los era remeter a um passado de glórias e tornar presente seus feitos que glorificavam a pátria portuguesa. Na publicação de número 2 de junho-julho de 1961 na seção Glórias das Letras Portuguesas, Mario F. Dias assinou um texto com o título Camões. Afirmava: "depois do êxito do nosso primeiro número, volto o meu pensamento para longe, ao lugar onde nasci e também em justa homenagem ao lírico Camões, aquele que foi infeliz no fim da vida" (LUSO-BRASILEIRA, 1961: 4). Trazer Portugal e seus mitos para o imaginário dos emigrados portugueses seria uma forma de alimentar a identidade portuguesa fora de Portugal. Isso seria essencial para que também as políticas do país luso se efetivassem por meio do cidadão português espalhado pelo mundo. A identificação com elementos da cultura portuguesa aproximava os portugueses do seu passado e das questões do seu presente.

No texto, escrito em página inteira, sob o título A Igreja de Fátima do Estreito Mário Dias, que nos primeiros números assinava grande parte dos artigos, ao final da matéria sobre as aparições em Fátima e a coincidência de ter na cidade para onde emigrou uma Igreja de Fátima, apresentava uma entrevista com o padre da paróquia. Nesta entrevista algumas perguntas chamam a atenção como: “- O que nos diz da expulsão dos padres em Cuba?" e “- O que entende o senhor por Comunismo?", para as quais o padre responde que “- É uma doutrina social que procura estabelecer regimes de governo contrários aos interesses democráticos e contrários aos direitos do indivíduo e aos direitos de Deus" (LUSO-BRASILEIRA, 1961: 5). Respostas que já eram presumidas e 
meios para elucidar a posição da revista em relação ao tema Comunismo e Igreja Católica. Demonstrar nas matérias a defesa do pensamento da Igreja Católica ligava a revista às posições do Estado Novo português na questão religiosa. Diante do contexto da Guerra Fria, a participação da Igreja Católica no Estado Novo se afirmava, efetivamente, por meio de uma postura de combate entre o bem e o mal, ou entre "civilização cristã" e o comunismo (SIMPSON, 2012).

Ao noticiar informações políticas e sociais sobre o país luso na seção Notícias de Portugal a revista faz apontamentos sobre a situação da guerra colonial em Angola:

Gesto louvável em favor das crianças de Angola, promoção do nosso colega Diário Popular. Todos os lares de Portugal se abrem numa iniciativa digna, para serem recebidas as crianças angolezas. Até que seja amainado o temporal dos terroristas que matam e atacam as aldeias das famílias da colônia, essas crianças estarão em segurança. (LUSOBRASILEIRA, 1961: 20)

Novamente a Luso-Brasileira se posicionando em relação às guerras coloniais, e ao abordar o tema vale-se do termo "terroristas" se referindo aos movimentos de independência em Angola, opondo colonos a nativos que lutavam pela autodeterminação, classificando-os como terroristas. E em outro pequeno texto desta seção prossegue:

Continuam seguindo para a província ultramarina de Angola mais tropas com o propósito de repelir os invasores. Sabemos que os nossos colonos estão em perigo, mas os portugueses jamais perderam uma batalha. Daqui enviamos o nosso louvor aos bravos patrícios que marcham para a frente de combate e que Deus os proteja sempre (LUSOBRASILEIRA, 1961: 20).

Ao mesmo tempo que apresentava a notícia assumia uma posição, a partir da postura a respeito da situação da guerra colonial. Colocava-se na defesa dos colonos em Angola, não do conjunto da sua população. A LusoBrasileira apresentava uma posição oficial, em comum acordo com a postura do regime de Salazar em relação às colônias, e procurava reunir em torno de si os portugueses emigrados no apoio a essa ideia contra a independência de 
Angola. Não queria unicamente oferecer a notícia de forma despolitizada, mas reforçar a sua posição de maneira a aglutinar os que estivessem de acordo com ela.

Na edição número 3 da revista o corpo editorial já aparece com novos nomes e Osvaldo Melo é um destes. Um agradecimento foi feito para a Impressora Modelo, de propriedade de Orivaldo Stuart e Cia pela forma como vinha editando a revista. Havia um constante esforço nas matérias em registrar a vontade da revista de buscar a amizade entre lusos e brasileiros, reforçar os laços de amizade entre os dois povos. Em matéria com o título Exclusiva, escrita pelo Rev. Messias Anacleto Rosa o tema que ocupa uma página inteira é Cuba e Fidel Castro. São vários os elogios que o Reverendo tece a Fidel Castro:

Fidel Castro, elemento jovem, culto, erudito, provavelmente um reflexo da humanidade atual, um homem insatisfeito com a situação política de seu povo. Isto não é um homem apenas, nós vivemos na época que não é apenas a era interplanetária mas que também pode ser chamada a época, a era da insatisfação (LUSO-BRASILEIRA, 1961: 5).

Ao elogiar Fidel Castro como "insatisfeito" e transformador, o reverendo expõe uma visão mais progressista da história de Cuba, de certa maneira distinta da percepção política que a Luso-Brasileira apresentava em edições anteriores. E prossegue: "caída, derrota de Fulgêncio Batista, vitória de Fidel Castro, final de um velho regime, fim de uma velha vida, implantação de um novo costume, começo de uma nova política, princípio de uma nova era, para um pequeno povo" (LUSO-BRASILEIRA, 1961: 5). A defesa de Fidel Castro e dos novos rumos implantados em Cuba são apontadas no texto de maneira contundente, contrariamente ao que a revista defendia em relação às ameaças comunistas sofridas pelas colônias africanas. Todavia, ao tratar do "elemento humano, Fidel Castro", abordava a questão de outro modo, com receio das suas ações no governo de Cuba, “[...] pois que ainda não ofereceu ao povo a oportunidade de uma eleição livre, demonstração de democracia [...]" (LUSO-BRASILEIRA, 1961: 5). Interessante perceber esse texto conflitante sob alguns aspectos, pois apresentava a situação de Cuba de forma laudatória, numa revista conservadora, apoiadora de uma ditadura, mas contrária à falta de 
democracia em Cuba. São os traços não tão nítidos da posição política da revista que vão se delineando pouco a pouco na publicação.

São comuns os textos que descrevem a vida do português Mario Fernandes Dias, editor da revista, além de cidades, cultura e costumes portugueses. No texto Lisboa da minha saudade ele se refere a seu "torrão natal", a "terra dos heróis marinheiros". Comenta sobre o dia a dia da vida do comércio do peixe em Lisboa e a vida corrida dos operários na hora do almoço. Sobre o assunto das conversas dos amigos que tocam em temas como o futebol do Benfica ou a viagem do homem à Lua. Ao discorrer sobre o fado afirmava que "Lisboa tem coisas notáveis que jamais poderei esquecer. Os moços adoram o fado, e não há cão nem gato que não conheça a Amália e o Alberto Ribeiro" (LUSO-BRASILEIRA, 1961: 13). Estas temáticas fazem pensar a partir das proposições de Heloisa Paulo que

A 'Pátria' é [...] um ideal, uma imagem, ou uma utopia que a distância torna, cada vez mais, 'intocável'. Como 'idealização', ela não é passível de críticas, sendo impossível, de imediato, a aceitação de uma outra imagem mais real, que pusesse fim à esta visão. Venerada, a 'Pátria' é, portanto, motivo de culto, traduzido numa devoção à aldeia natal, mas que passa por referenciais mais 'intelectualizados', como a história, com as suas datas e heróis oficiais (PAULO, 2000: 274).

Este trecho é bastante significativo e exprime de forma elucidativa a relação que se cria entre o emigrado e sua "pátria" distante, a intensidade de sentimentos que se apresentavam quando se tratava de falar da sua terra natal, idealizada e "intocável”. O país que lá ficou não é passível de problemas políticos nem sociais. Como quando afirma que "Portugal e Espanha, banindo a anarquia do seu solo, impuseram-se como nações economicamente organizadas". Portugal será mais do que nunca motivo de veneração aos olhos do emigrado, não há espaço nem motivo para críticas, pois seria preciso lembrar também que quem emigrava era um representante de Portugal no país para o qual emigrou e, portanto, cabia-lhe fazê-lo da melhor forma, para mostrar ao mundo a grandeza e o progresso do "império português". 
Nos dezoito anos de publicação, em especial do ano de 1961 a 1974, durante a vigência do Estado Novo, a revista serviu como um componente que trouxe Portugal aos emigrantes portugueses em algumas cidades do Brasil e colônias portuguesas. Contribuiu para que portugueses distantes de Portugal pudessem manter-se vinculados ao seu país e a todo o imaginário da portugalidade para assim fazerem parte daquele universo no Brasil e "honrar" um pretenso compromisso para com o regime.

A pesquisa possibilitou compreender a Revista Luso-Brasileira circulou em Estados no Brasil com o intuito de reunir portugueses emigrados em torno das ideias do Estado Novo, estimular o imaginário do ser português, engajar defensores do colonialismo português na África e propagar as ideias do regime para as comunidades luso-brasileiras. Mobilizava diversos elementos ligados ao ideário do regime, por vezes apenas indiretamente ligados com questões políticas, e evocavam um conjunto de referências ao mundo português, seus personagens, suas tradições, seus locais emblemáticos. $\mathrm{O}$ investimento em imagens específicas sobre símbolos portugueses na publicação era uma forma de criar as ligações entre o regime e os emigrados e que demonstram as inclinações da publicação e o impulso político do editor português em estreitar seu compromisso com o Estado Novo por meio do impresso.

\section{Referências}

ANDERSON, Benedict. Comunidades Imaginadas: Reflexões sobre a origem e a Expansão do Nacionalismo. $3^{\mathrm{a}}$ reimpressão. São Paulo: Companhia das Letras, 2008.

BACZKO, Bronislaw. A imaginação social In: LEACH, Edmund et alli. Anthropos-Homem. Lisboa, Imprensa Nacional/Casa da Moeda, 1985.

BARNES, J. A. Redes sociais e processo político. In: FELDMAN-BIANCO, Bela (Org.). Antropologia das Sociedades Contemporâneas. São Paulo: Global, 1987: 159 - 194.

CABRITA, Filipa. Turismo para a construção de uma paisagem cultural: sedução, símbolo, autenticidade. Revista de Cultura Arquitectonica. Março de 2010. Disponível em: <https://digitalis- 
dsp.uc.pt/bitstream/10316.2/37221/3/Turismo\%20para\%20a\%20construcao\%2 0de\%20uma\%20paisagem\%20cultural.pdf> Acesso em 15 jul. 2018.

CASTELO, Claudia. "Novos Brasis" em África: desenvolvimento e colonialismo português tardio. Varia Historia, Belo Horizonte, 2014, vol. 30, $\mathrm{n}^{\mathrm{o}}$ 53, p.507-532. Disponível em: <http://dx.doi.org/10.1590/S0104$87752014000200009>$ Acesso em ago. 2020.

GALVANESE, Marina Simões. A Junta da Emigração: Os discursos sobre a emigração e os emigrantes no Estado Novo do Pós-Guerra (1947-1970). 2013. Dissertação (Mestrado em História) Universidade de Coimbra, Coimbra, 2013.

GONÇALVES, Eduardo Cordeiro. Turismo de massas em Portugal: da destradicionalização à desestruturação. Barataria - Revista CastellanoManchega de Ciencias Sociales, 2012, $\mathrm{n}^{\circ}$ 14, pp. 99-105, Disponível em: <http://dx.doi.org/10.20932/barataria.v0i14.104> Acesso em 10 fev. 2018.

KOLLERITZ, Fernando. Testemunho, juízo político e história. Rev. Bras. Hist., São Paulo, v. 24, n. 48, p. 73-100, 2004. Disponível em $<$ http://www.scielo.br/scielo.php?script=sci_arttext\&pid=S0102-

01882004000200004\&lng=en\&nrm=iso $>$. Acesso em 09 Ago. 2020.

KOSELLECK, Reinhart. Estratos do tempo. Estudos sobre história. Rio de Janeiro: Contraponto/PUC-Rio, 2014.

LANG, Alice B. da Silva Gordo. Portugueses em São Paulo: memórias e identidade. In: TRINDADE, M. Beatriz e CAMPOS, M. Cristina S. de Souza. Olhares Lusos e Brasileiros. São Paulo: Ed. Usina do Livro, 2003.

LE GOFF, Jacques. História e memória. Campinas, SP Editora da UNICAMP, 1990.

LOURENÇO, Eduardo. A nau de Ícaro e imagem e miragem da lusofonia. São Paulo: Companhia das Letras, 2001.

MACIEL, Cármen Liliana Ferreira. A Construção da comunidade lusófona a partir do antigo centro. Micro-Comunidades e Práticas da Lusofonia. 2010. Dissertação (Doutorado - Sociologia), Universidade Nova de Lisboa, Lisboa, 2010.

OLIVEIRA, Lúcia Lippi. Portugal e Brasil: uma relação tão delicada. In: ANPUH - XXII Simpósio Nacional de História, 2003, João Pessoa. Anais [...]. Disponível em: $<$ http://www.seer.ufu.br/index.php/artcultura/article/view/1377/1246> Acesso em 9 ago. 2016. 
PAULO, Heloísa. "Aqui também é Portugal”: A colônia portuguesa do Brasil e o Salazarismo. Coimbra: Quarteto, 2000.

RIBEIRO, Carla Patrícia Silva. O turismo e a projeção da vida nacional por António Ferro: o papel dos concursos. Revista População e Sociedade, Porto, Dezembro 2015, vol.24, p. 93-113. Disponível em: <http://recipp.ipp.pt/bitstream/10400.22/8918/1/Populac\%CC\%A7a\%CC\%83o $\% 20 \mathrm{e} \% 20$ Sociedade\%20-\%2024.pdf> Acesso em 10 jan. 2018.

SANTOS, Ivete Sobral dos. A Junta Nacional de Emigração e a política de emigração no Estado Novo. 2014. Tese (Doutorado em História Contemporânea), Lisboa, Universidade Nova de Lisboa, 2014.

SIMPSON, Duncan. A Igreja Católica e o Estado Novo de Salazar. Locus: Revista de História, Juiz de Fora, 2012, v.18, n.1, p. 89-110. Disponível em: $<$ https://locus.ufjf.emnuvens.com.br/locus/article/view/1990/1435> Acesso em 7 jan. 2018.

SIRINELLI, Jean-François. Os intelectuais. In. RÉMOND, René. (Org.) Por uma História Política. Rio de Janeiro: Editora FGV, 2003.

Fontes

O SÉCULO ILUSTRADO, 1950 (Hemeroteca Municipal de Lisboa)

JUNTA DE EMIGRAÇÃO. Nós, os emigrantes. Lisboa, Ministério do Interior, 1954.

REVISTA LUSO-BRASILEIRA, $\mathrm{n}^{\circ}$ 1, maio, 1961. Biblioteca Pública do Estado de Santa Catarina

REVISTA LUSO-BRASILEIRA, $n^{\circ}$ 2, jun/jul, 1961. Biblioteca Pública do Estado de Santa Catarina

REVISTA LUSO-BRASILEIRA, $n^{\circ}$ 3, agosto, 1961. Biblioteca Pública do Estado de Santa Catarina

REVISTA LUSO-BRASILEIRA, nº12, fev/mar, 1963. Biblioteca Pública do Estado de Santa Catarina

FAMILY SEARCH - Disponível <https://www.familysearch.org/ark:/61903/3:1:939X-HS9M-

$\mathrm{Z}$ ?i=61\&cc=1932363> Acesso em 20 ago 2017.

Recebido em: 14 de maio de 2020

Aceito em: 28 de julho de 2020 